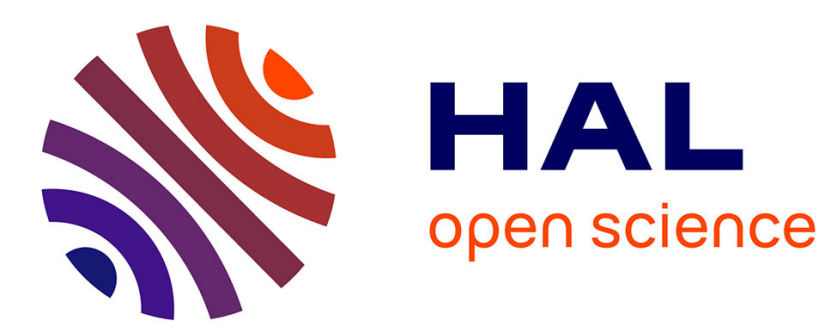

\title{
Low Temperature Behaviour of Laser Diodes
}

M. Bibey, Nour Eddine Bourzgui, B. de Cremoux, J. Carru, M. Krakowski, P.

Richin, P. Tabourier, R. Blondeau

\section{To cite this version:}

M. Bibey, Nour Eddine Bourzgui, B. de Cremoux, J. Carru, M. Krakowski, et al.. Low Temperature Behaviour of Laser Diodes. Journal de Physique IV Proceedings, 1996, 06 (C3), pp.C3-237-C3-243. 10.1051/jp4:1996336 . jpa-00254254

\section{HAL Id: jpa-00254254 https://hal.science/jpa-00254254}

Submitted on 1 Jan 1996

HAL is a multi-disciplinary open access archive for the deposit and dissemination of scientific research documents, whether they are published or not. The documents may come from teaching and research institutions in France or abroad, or from public or private research centers.
L'archive ouverte pluridisciplinaire HAL, est destinée au dépôt et à la diffusion de documents scientifiques de niveau recherche, publiés ou non, émanant des établissements d'enseignement et de recherche français ou étrangers, des laboratoires publics ou privés. 


\title{
Low Temperature Behaviour of Laser Diodes
}

M.B. Bibey, N. Bourzgui*, B. de Cremoux, J.C. Carru*, M. Krakowski, P. Richin, P. Tabourier* and R. Blondeau

Thomson-CSF LCR, Domaine de Corbeville, 91404 Orsay Cedex, France

* IEMN, Cité Scientifique, BP 69, 59652 Villeneuve d'Ascq Cedex, France

\begin{abstract}
Low temperature behaviour of InGaAsP laser diode is studied. The laser is a Fabry-Pérot type with a Buried Heterostructure. A large improvement of threshold current is obtained as the temperature decreases. The exponential variation of Ith is verified and a T0 value of $69 \mathrm{~K}$ is deduced. The intrinsic resonant frequency is measured with noise analysis. This resonance varies as the square root of the net injected current. The slopes of these curves are found to increase dramatically with decreasing temperature. The $3 \mathrm{~dB}$ bandwidth experiments are also performed, leading in the same way, to a large increase of the slopes with cooling but package parasitics limit the maximum achievable bandwidth. The influence of the laser parasitics, such as the roll-off phenomenum, is also underlined.
\end{abstract}

\section{INTRODUCTION}

In some space applications, electronics devices and circuitry may be at cryogenic temperature. Moreover with progress toward economical and compact cryo-coolers, cooled laser diode transmitters show great potential for high speed optical fibre communication system. There is then a new interest in studying the laser properties at low temperatures [1]. This paper reports measurements and analysis of low temperature behaviour of laser diodes. We first present static experiments including measurements of threshold currents, electricalto-optical conversion efficiency and device series resistance. Then we study the resonant frequency deduced from noise measurement. Finally we present the dynamic behaviour of laser diodes with the frequency modulation response and the influence of parasitics.

These experiments are only performed with one specific diode and despite its good performances, measurement limitations are reached because of the experimental set-up and diode submount. However further work on this subject will permit to solve these problems.

\subsection{Experimental set-up}

The laser diode is packaged with microwave-connector submount which allows characterization from DC to only a few gigahertz. The laser diode support is mounted on the cold plate of a cryogenerator using helium gaz. The system is capable of both static and dynamic measurements and temperature regulation is used from $300 \mathrm{~K}$ to below $77 \mathrm{~K}$. The output light is collimated directly at the output of the laser by a Selfoc microlens. The parallel beam crosses an optical window and then, is coupled through an objective lens to a $30 \mu \mathrm{m}$ fast PIN photodiode that allows electrical frequency domain analysis.

The threshold current measurements are performed separately with large area photodetectors. Experiments are done with InGaAsP Fabry-Pérot lasers. The structure is Buried Ridge Stripe 
(BRS) Heterostructure [2] with strained multiple quantum wells in the active region. The emission wavelength is $1.55 \mu \mathrm{m}$.

\section{STATIC EXPERIMENTS}

\subsection{Light versus current characteristics}

The cw optical power is measured at different temperatures for various injected currents. Typical P(I) curves can be plotted (fig. 1) and threshold current is deduced. It is defined, on the tangent to the $P(I)$ curve, as the current value obtained for $P=0 \mathrm{~mW}$. For better reading only a few temperatures are represented on fig. 1 .

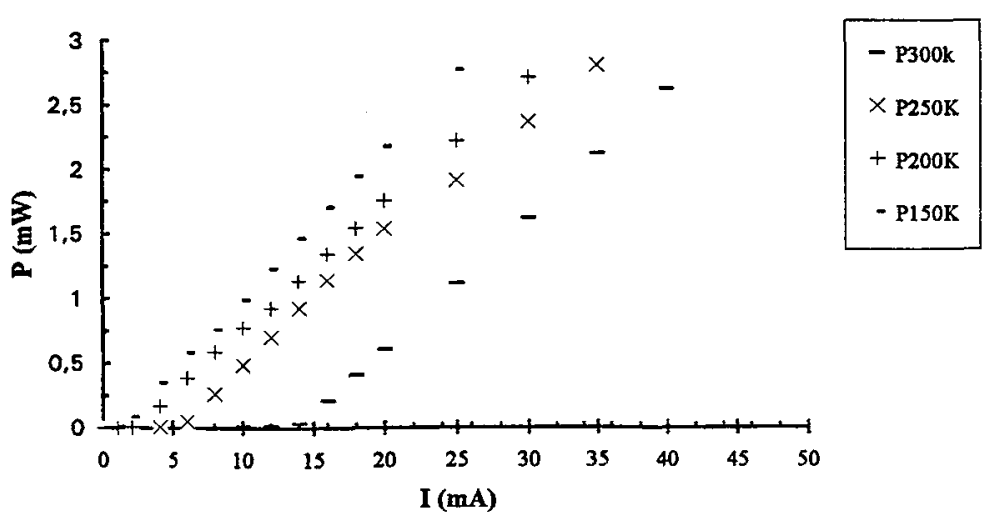

Figure 1: Output optical power versus injected current at various temperatures.

On fig. 1, the threshold current decreases considerably. From $300 \mathrm{~K}$ to $50 \mathrm{~K}$, it decreases from around $13.6 \mathrm{~mA}$ to $0.3 \mathrm{~mA}$. The electrical to optical conversion efficiency, defined as the slope of the tangent near threshold, does not vary significantly when cooling. We get $0.1 \mathrm{~W} / \mathrm{A}$ at $300 \mathrm{~K}$ against $0.11 \mathrm{~W} / \mathrm{A}$ at $77 \mathrm{~K}$. These values does not correspond to the real laser efficiency, but they take into account the coupling losses. We will see in section 3 that a conversion efficiency can also be calculated for any current and can be linked to the optical losses of the link.

Some of the possible origins of the threshold current decrease with $\mathrm{T}$, include Auger recombinations, inter-valence band absorption and carrier leakage [3].

The threshold current is usually found to be given by the expression [4]:

$$
\text { Ith }-\operatorname{Exp}(\mathrm{T} / \mathrm{T} 0)
$$

with T0 the characteristic temperature of the material. The deduced T0 value from fig. 2 is 
about 69K which fits quite well with previous results for these materials [4].

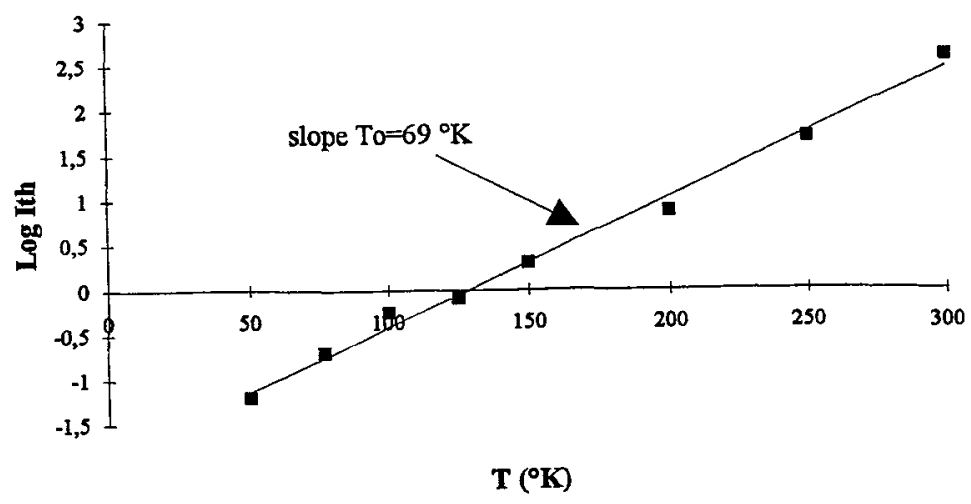

Figure 2: Exponential temperature dependence of threshold current.

\subsection{Laser series resistance}

As we will explain later in this paper, package parasitics limit the maximum bandwidth of this device.

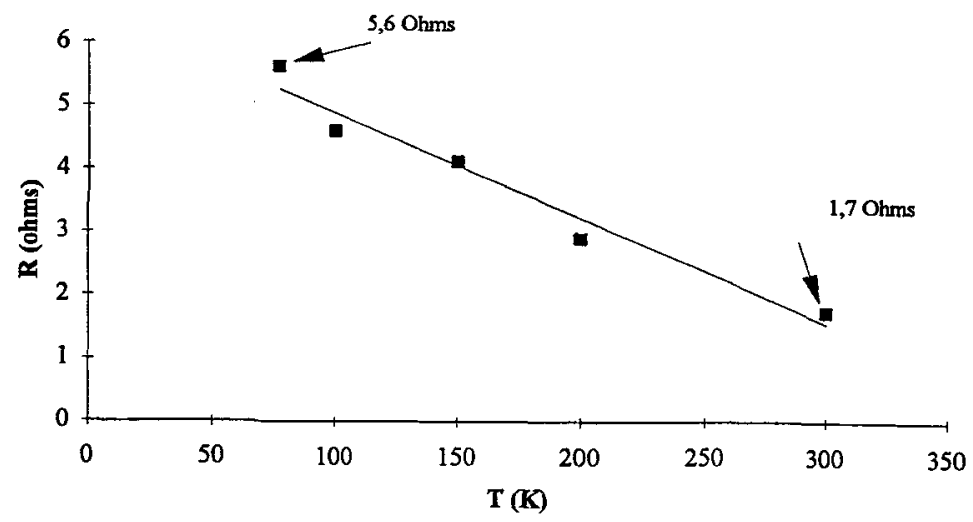

Figure 3: variation of the device series resistance with temperature.

But the laser series resistance itself may also be a limiting factor. So we derive it from the linear portion of the current-voltage measurements at different temperatures.

On fig. 3 the series resistance is about $1.7 \mathrm{ohms}$ at $300 \mathrm{~K}$ and increases to $5,6 \mathrm{ohms}$ at $50 \mathrm{~K}$. 
This may involve with the device capacitance some parasitic low frequency cut-off that limits seriously the bandwidth [5].

\subsection{Intrinsic resonant frequency obtained with noise analysis}

Semiconductors lasers, inherently possess an intrinsic resonance as a result of the dynamic interaction between the inverted population and the optical field [6].

The resonant frequency is an important laser parameter. For high speed communication system it is crucial to get large resonant frequency. Indeed a necessary, but not sufficient, condition to get a large bandwidth is to get a large intrinsic resonant frequency. The interest in studying Fr rather than directly studying the bandwidth is that we can measure it without laser modulation. Indeed, the presence of this natural resonance can be revealed by several methods and in particular by the existence of a resonant peak in the frequency spectrum of the noise fluctuations in the cw output intensity.

We can also find this resonance in the modulation response spectrum (see section 3 ).

The experimental set-up is nearly the same as previously. A cw current is injected into the laser. The noise fluctuations at the output are measured with a noise figure meter.

On a typical evolution of the resonance frequency with the injected current we can observe a considerable increase in Fr while decreasing temperature, not in term of absolute value but regarding the current needed to reach it. Indeed for instance at $300 \mathrm{~K}, \mathrm{Fr}=2.5 \mathrm{GHz}$ is reached for $25 \mathrm{~mA}$ injected, whereas at $77 \mathrm{~K}$, only $1.3 \mathrm{~mA}$ are needed. This aspect appears clearer with the calculations of the slopes of the curves on fig. 4 .

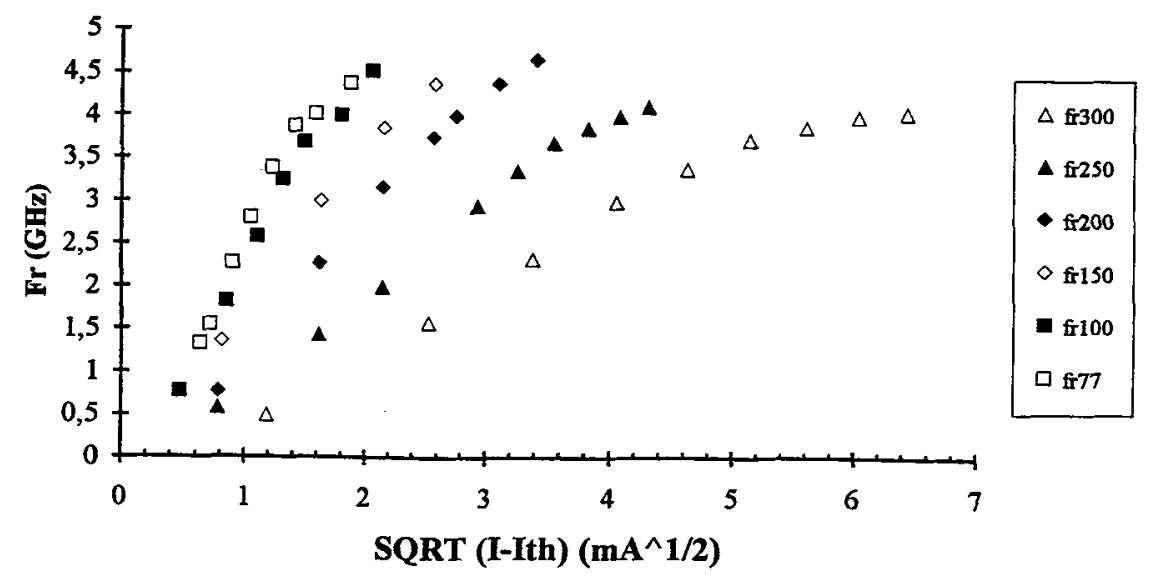

Figure 4: The variation of the resonant frequency with the square root of the net injected current at various temperatures. Note the slope change with temperature.

The resonant frequency is usually known to vary as the square root of the net injected current [7]:

$$
\mathrm{Fr}=1 / 2 \pi * V\left(\mathrm{v}_{\mathrm{g}} \Gamma \mathrm{g}_{\mathrm{o}}\left(\mathrm{I}-\mathrm{I}_{\mathrm{th}}\right) / \mathrm{qV}\right)
$$


with $g_{0}$ the differential gain, $v_{g}$ the light group velocity, $\Gamma$ the optical confinement factor, $V$ the active volume and $\mathrm{q}$ the electron charge.

On fig. 4 we plot the resonant frequencies as a function of the square root of the net injected current for different temperatures.

The variation of $\mathrm{Fr}$ is quasi linear and one can deduce the large increase of the slope of these curves with decreasing temperature. At $300 \mathrm{~K}$ we get $0.44 \mathrm{GHz} / \mathrm{mA}$ against $1,67 \mathrm{GHz} / \mathrm{mA}$ at $175 \mathrm{~K}$ and $3 \mathrm{GHz} / \mathrm{mA}$ at $77 \mathrm{~K}$. This is really important for high speed communications systems.

\section{MODULATION BANDWIDTH}

The small signal response of the laser diode is studied in this section. We do not find record values but we extract some interesting behaviours and underlines some problems.

First it is important to take into account the conditions of these experiments: here are the first experiments we have done on the subject with a single laser structure. So the limitations found are relative to this laser structure and this specific experimental set-up and laser submount.

A sinusoidal modulation is surimposed to the $\mathrm{cw}$ pumping. The output power is measured on a network analyzer as a function of the frequency.

The bandwidth at $-3 \mathrm{~dB}$ is determined at various temperatures for different injected currents. On fig. 5 we plot this bandwidth versus the square root of the net current.

One can notice that there are only a few experimental points at low temperature and that the bandwidth is limited to a few gigahertz.

First the laser submount used here, does not allow experiments with frequencies higher than $6.5 \mathrm{GHz}$. That imposes a serious limit for maximum bandwidth measurements but it does not involve the laser performances and it can be easily overcome by using a more appropriate microwave submount. So from $300 \mathrm{~K}$ to $250 \mathrm{~K}$ this submount cut-off limits the maximum bandwidth.

As $\mathrm{T}$ decreases, laser parasitics, as the roll-off, start to become really significant and prevent any further bandwidth measurements.

For temperatures less than $175 \mathrm{~K}$ it appears to be really difficult to determine the bandwidth at $-3 \mathrm{~dB}$ on the experimental spectrum, at any polarization currents.

Above $175 \mathrm{~K}$ however, the determination of bandwidth is possible but the maximum achievable value is greatly reduced compared to $300 \mathrm{~K}$.

The low frequency roll-off [8] is a responsible parameter. This parasitic phenomenum is supposed to be linked to the dramatic increase of the laser series resistance. So the frequency cut-off at $1 / 2 \pi R C$, is decreased.

It is particularly important for Buried Heterostructure Fabry-Pérot lasers as our device.

However the $3 \mathrm{~dB}$ bandwidth evolution is improved at low temperatures and can be quantified, in the same way as the resonant frequency in section 2, in terms of the current value needed to reach a given bandwidth value: for instance $F_{3 \mathrm{~dB}}=2.1 \mathrm{GHz}$ is obtained with $20 \mathrm{~mA}$ at $300 \mathrm{~K}$ and $3 \mathrm{~mA}$ at $150 \mathrm{~K}$.

The variation with the square root of current is quasi linear. For the slope improvement, we get $0.74 \mathrm{GHz} N \mathrm{~mA}$ at $300 \mathrm{~K}$ against $2,4 \mathrm{GHz} / \mathrm{mA}$ at $175 \mathrm{~K}$. 
One can notice that the modulation bandwidth is approximatively 1,5 times greater than the resonant frequency.

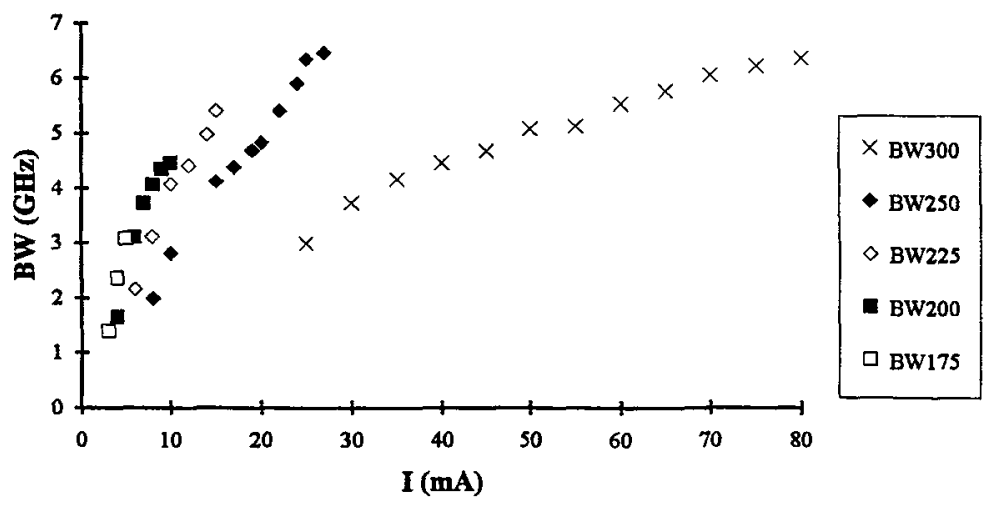

Figure 5: The temperature dependence of the modulation bandwidth. Note the slope increase with decreasing temperature.

The output power level measured on a network analyzer is related to the insertion loss of the optical link. Indeed the losses are defined as the ratio of the electrical output power to the electrical input power. A loss improvement of $2.1 \mathrm{~dB}$ is observed from $300 \mathrm{~K}$ to $150 \mathrm{~K}$. This is directly linked to the enhancement of the relative electrical-to-optical conversion efficiency, measured for a given current.

At $300 \mathrm{~K}$ for $65 \mathrm{~mA}$ it was $0.07 \mathrm{GHz} / \mathrm{mA}$ and at $150 \mathrm{~K}$ for $3 \mathrm{~mA}$ it was $0.09 \mathrm{GHz} / \mathrm{mA}$. So in $\mathrm{dB}$, the conversion efficiency improvement is: $20 * \log (0.09 / 0.07)=2.18 \mathrm{~dB}$.

\section{CONCLUSION}

For some aspects, the laser behaviour is improved at low temperatures. Enhancement of threshold currents from $13.6 \mathrm{~mA}$ to $0.3 \mathrm{~mA}$ between $300 \mathrm{~K}$ and $50 \mathrm{~K}$ is observed. The conversion efficiency, defined near threshold, is nearly constant in this range of temperatures.

The resonant frequency evolution is also increased. The slope of the curves: Fr versus the square root of the net current varies from $0.44 \mathrm{GHZV} / \mathrm{mA}$ to $3 \mathrm{GHz} / \mathrm{mA}$ between $300 \mathrm{~K}$ and $77 \mathrm{~K}$.

A bandwidth evolution enhancement is also measured. But the maximum achievable value is limited.

However a better performance in the bandwidth value is expected if submount parasitics are suppressed. Moreover experiments with different laser structures, such as the ridge structure, that is known to be less sensitive to the roll-off phenomenum, will be performed to examine the influence of the laser parasitics. 
The noise characteristics are also of great interest. Our future work will permit to study the laser diode noise behaviour at low temperature and it is expected to exhibit large reduction with cooling.

\section{References}

[1] R.C. Yu, R. Nagarajan, T. Reynolds, J.E. Bowers et al, "Ultrahigh speed cryogenic laser diodes for broadband optical fibre link applications",IEEE MTT-s Digest, 1995, p.45. [2] M. Krakowski, R. Blondeau, Kazmierski, Razeghi et al, "high yield manufacture of very low threshold, high reliability, $1.3 \mu \mathrm{m}$ buried heterostructure laser diodes grown by metal organic vapor deposition", J. Light. Techn., LT4, 10, 1986, p.1470.

[3] N.K. Dutta, J. Lopata, D.L. Sivco, A.Y. Cho, "Temperature dependence of threshold of strained quantum well lasers", Appl. Phys. Lett., 58 (11),1991, p.1125.

[4] J. Pankove, Optical Processes in Semiconductors (Dover, New York, 1975).

[5] L.E. Eng, A. Sa'ar, T.R. Chen, I. Grave, N. Kuze, A. Yariv, "Microamperemetre threshold current operation of GaAs and strained InGaAs quantum well lasers at low temperatures (5K), Appl. Phys. Lett., 58 (24), 1991, p.2752.

[6] T. Paoli, "Near-threshold behaviour of the intrinsic resonant frequency in a semiconductor laser", J. Quantum Electron., 15 (8), 1979, p.807.

[7] R. Yu, R. Nagarajan, T Reynolds, A. Holmes, J.E. Bowers et al "Ultrahigh speed performance of a quantum well laser at cryogenic temperatures", Appl. Phys. Lett., 65 (5), 1994, P.528.

[8] R. Nagarajan, M;Ishikawa, T. Fukushima, R. S. Geels., J. Bowers, "High speed quantum-well lasers and carrier transport effects", J. Quantum Electro., 28 (10), 1992, p. 1990 . 